Sosyo

Ekonomi

Özel Sayı

2010-EN

\title{
Is There a Stochastic Trend in European Union Emission Trading Scheme Prices?
}

Don BREDIN

Cal MUCKLEY

don.bredin@ucd.ie

cal.muckley@ucd.ie

\section{Avrupa Birliği Emisyon Ticaret Programı Fiyatlarında Stokastik Bir Eğilim Var Mı?}

\begin{abstract}
The European Union's Emission Trading Scheme (ETS) is the key policy instrument of the European Commissions Climate Change Program aimed at reducing greenhouse gas emissions to eight percent below 1990 levels by 2012. The key asset traded under the scheme is the European Union Allowance (EUA). To further curtail greenhouse gas emissions the EU Allowance prices should follow a stationary path about a persistent upward trend. In this vein, this article finds evidence to the contrary indicating the presence of a stochastic trend (a unit root) in EU Allowance prices during the period from April 2005 through to July 2009. This finding is indicative of incoherence between the European Union ETS de jure policy, with regard to transiting to a low carbon economy, and EUA price behavior.

Key Words $\quad$ : $\mathrm{CO}_{2}$ Prices, Energy, EU ETS, Kyoto Protocol, Unit Root.

JEL Classification Codes : Q49, G12, G15.

Özet

Avrupa Birliği'nin Emisyon Ticaret Programı sera gazı emisyonunu 2012'ye kadar 1990'daki seviyelerinin yüzde sekiz aşağısına düşürmeyi amaçlayan Avrupa Komisyonu İklim Değişikliği Programının temel politika aracıdır. Bu program altında ticareti yapılan unsur Avrupa Birliği Tahsisatıdır. Sera gazı emisyonlarını daha da fazla düşürmek için Avrupa Birliği Tahsisat fiyatlarının yukarı doğru sürekli bir artış eğiliminde durağan bir patika izlemesi gerekmektedir. Ne var ki, makalemizde bunun tersine Nisan 2005'ten Temmuz 2009'a kadarki dönem boyunca Avrupa Birliği Tahsisat fiyatlarında stokastik bir eğilimin (bir birim kök) mevcut olduğunu gösteren bir delil bulunmuştur. Bu durum düşük karbonlu bir ekonomiye geçiş sağlamayı hedefleyen Avrupa Birliği Emisyon Ticaret Programına dair yasal politika ile Avrupa Birliği Tahsisatı fiyat davranışı arasında bir tutarsızlık olduğunu göstermektedir.
\end{abstract}

\section{Anahtar Sözcükler $\quad: \quad \mathrm{CO}_{2}$ Fiyatları, Enerji, Avrupa Birliği'nin Emisyon Ticaret} Programı, Kyoto Protokolü, Birim Kök. 
Don BREDIN \& Cal MUCKLEY 


\section{Introduction}

In January 2005 the European Union (EU) Emission Trading Scheme (ETS) was introduced formally. The scheme has been instigated as part of the EU agreement to cut worldwide emissions of carbon dioxide $\left(\mathrm{CO}_{2}\right)$ within the Kyoto Protocol. Under the Kyoto Protocol, the EU has committed to reduce greenhouse gas emissions by eight percent (relative to 1990 levels) by 2008-2012. The scheme issues a restricted amount of emission allowances (EUAs or carbon credits) to firms on an annual basis. At the end of the year firms must hold the required amount of emission permits to meet their emissions of $\mathrm{CO}_{2}$ over the previous year. ${ }^{1}$ The ETS allows firms to trade the amount of emission permits that they hold and as a result has applied a market value to this externality. In the EU ETS context the first phase of trading was 2005-2007 and the second phase, which coincides with the first compliance period of the Kyoto Protocol, is 2008-2012. The third European trading phase will commence in 2013. Non-compliance with the commitments results in a penalty of 40 (100) euros per tonne of $\mathrm{CO}_{2}$ produced without allowances for the first (second) commitment period. The aim of the ETS is that this cost will encourage firms to reduce their emissions.

Paolella and Taschini (2008) highlight that the ultimate aim of this scheme (as well as the US CAAA-Title IV scheme) must be to create an environment where there is a scarcity of allowances which will lead to mean reversion around an upward trend in prices. As a result, if the ultimate aim of this scheme is not to be frustrated, we should expect to see dissipative random shocks about a price series containing an upwardly inclined deterministic trend. However, evidence to the contrary indicates that the penalty for emitting carbon is not necessarily growing over time and hence emitters are not necessarily increasingly incentivated to diminish their output of $\mathrm{CO}_{2}$ emissions. Specifically, the finding of a stochastic trend (a unit root) in EUA prices would indicate that price behavior is not coherent with declared European Union policy to transit to a low carbon economy. Hence, following in the vein of Stern (2006), if this situation is not mitigated for, it will be increasingly difficult to stabilize the level of greenhouse gases in the atmosphere and the implications of global warming are expected to be severely harmful to the global economy. In fact, if it is established that EUA prices follow a stochastic trend, it would appear that there commendation of Stern (2006) that the benefits of strong, early action on climate change considerably outweigh the costs, is not taken seriously by the de facto European Union policy with regard to greenhouse gas emissions.

Nelson and Plosser (1982) conclude that a wide set of aggregate economic time series tend to exhibit a stochastic trend (or unit root). Essentially, these authors indicate that macroeconomic processes are non-stationary, that they are altered permanently rather than in a dissipative manner as a result of random shocks. This controversial conjecture

\footnotetext{
A report must be submitted to verify the emissions in any year by the $31^{\text {st }}$ March of the following year.
} 
has far reaching implications for our understanding of the evolution of these processes over time. In particular, whether a series is trend stationary or exhibits a unit root has ramifications for the modeling of these processes. ${ }^{2}$ As a result, since the seminal contributions of Dickey and Fuller $(1979,1981)$, econometricians have developed a variety of tests to establish the order of integration of a series and a variety of methods of eliminating nuisance parameters with a view to optimizing the power and size of their statistical hypotheses tests. Several of these tests for a unit root have been adopted in the extant literature, in the area of the carbon credit markets, with a view to better understanding price behavior over time.

The literature in the area of carbon credit markets is in its infancy, particularly concerning those contributions with an empirical focus. Alberola et al. (2008, 2009a, 2009b), examine, inter alia, the Power next spot prices (replaced by Blue next since January 2008), over periods extending from July 2005 through to April 2007, by adopting unit root tests including the augmented Dickey-Fuller $(1979,1981)$ test, the Phillips-Perron (1988) test, the Kwiatkowski et al. (1992) test and the Lee-Strazicich (2001, 2003) tests. They report that for these samples they are unable to reject the hypothesis that the processes are difference stationary that is that they contain a unit root. In contrast, Bredin and Muckley (2009), inter alia, adopt the Phillips-Perron (1988) test and report that they reject the null hypothesis of a stochastic trend in logarithmic EUA prices during a sample from the first phase of the scheme (July 1, 2005 to December 31, 2007). However, consistent with the Alberola et al. (2008, 2009a, 2009b) contributions, Daskalakis et al. (2009) find a unit root in the spot EUA price data from both Power next and Nordpool from 25th October 2005 through to 28th December 2007. The authors adopt the augmented Dickey-Fuller $(1979,1981)$ test, the Phillips-Perron (1988) test and the Kwiatkowski et al. (1992) test. Paolella and Taschini (2008) and Benz and Trück (2009) elect not to present unit root test results when examining spot prices extending from July 2005 through to May 2007 and January 2005 through to December 2006, respectively. The Benz and Trück (2009) data are sourced with a major broker in the energy industry, Spectron, and are observations on over-the-counter transactions. Paolella and Taschini (2008) do not disclose the source of their data. Taken together, the preponderance of unit root test results presented focus on a limited set of data containing spot prices and the results support the hypothesis that these prices follow a stochastic trend over time.

In this article, we extend the aforementioned published findings regarding the presence or otherwise of stochastic trends in EUA prices. In the first instance, we draw attention to the incoherence of a stochastic trend in EU Allowance prices with regard to the declared EU objective to significantly reduce greenhouse gas emissions and thus transit to a low carbon economy. Secondly, we focus exclusively on the most liquid exchanges, the

\footnotetext{
A unit root process necessarily exhibits infinite variance, thus violating a tenet of the well-known classical linear regression model and compromising the statistical properties of least-squares style regression estimation techniques.
} 
Bluenext exchange for spot EUA prices and the European Climate Exchange for derivative contracts. Thirdly, we extend the duration of data assessed, commencing in April 2005 through to July 2009. Fourthly, in contrast to the received literature, we consider a set of derivative futures contracts as well as spot prices with a view to better capturing expectations, with respect to the evolution of the EU Allowance price. Finally, our extension of the aforementioned published findings is accomplished by adopting an extensive set of stochastic trend (unit root) testing methodologies and discussing the complementary results obtained.

The remainder of this article is structured as follows. The next section provides a brief discussion concerning the various unit root testing methodologies adopted in the article. The following section introduces the data and describes the empirical results from the adopted unit root tests. Finally, concluding remarks are presented in the last section.

\section{Methodology}

The augmented Dickey-Fuller tests $(1979,1981)$, hence forth $A D F$ tests, discern whether time series are affected by transitory or permanent shocks. These tests are primarily concerned with estimating a value for $\gamma$. Specifically, the null hypothesis of $\gamma=0$ is tested against the alternative that $\gamma<0$

$$
\Delta y_{t}=\alpha+\beta t+\gamma y_{t-1}+\sum_{i=1}^{k} \delta_{i} y_{t-i}+\epsilon_{t}
$$

As per convention, the $\Delta$ symbol denotes the first difference of the examined series, $t$ is the time trend variable and $k$ is the number of lags which are added to the model to remove autocorrelations from the residuals, $\epsilon_{t}$. The number of lags is parsimoniously estimated via a minimization of the Bayesian Information Criterion (BIC). A variety of alternative hypotheses are specificied by the inclusion or exclusion of the deterministic components. The Phillips-Perron (1988) test, henceforth the $P P$ test, is nonparametric with respect to nuisance parameters and hence accommodates heterogeneously distributed data. Elliot et al. (1996), henceforth ERS, show that where a deterministic component is present, considerable improvements in statistical power can be attained by modifying the estimation of the parameters characterizing the deterministic component. Their modified Dickey-Fuller test provides the best over-all performance under the stochastic specification assessed, which includes the assumption of normally distributed errors.

However, as Perron (1989) indicates the $A D F$ test is biased in the presence of breaks towards the non rejection of the null hypothesis of a unit root. The Perron (1989) correction, outlined in equations (2) through (4), allows for a break under both the null and alternative hypotheses 


$$
\begin{aligned}
& \Delta y_{t}=\alpha+\alpha_{1} I D_{t}+\lambda C D_{t}+\beta_{1} t+\gamma y_{t-1}+\sum_{i=1}^{k} \delta_{i} y_{t-i}+\epsilon_{t} \\
& \Delta y_{t}=\alpha+\beta_{0} T D_{t}+\beta_{1} t+\gamma y_{t-1}+\sum_{i=1}^{k} \delta_{i} y_{t-i}+\epsilon_{t} \\
& \Delta y_{t}=\alpha+\alpha_{1} I D_{t}+\lambda C D_{t}+\beta_{0} T D_{t}+\beta_{1} t+\gamma y_{t-1}+\sum_{i=1}^{k} \delta_{i} y_{t-i}+\epsilon_{t}
\end{aligned}
$$

Where the intercept dummy, $I D_{t}$, denotes a change in the level; $I D_{t}=1$ if $(t>$ $B D$, the break date) and zero otherwise. The trend regression coefficient dummy, $T D_{t}$, denotes an alteration in the slope of the deterministic trend function. Specifically, $T D=t-$ $B D$ (or $T D_{t}=t$ ) if $t>B D$ and zero otherwise. The crash dummy, $C D$, is equal to 1 if $t=$ $T B+1$, and zero otherwise. The specifications (2) through (4) include a unit root with a break under the null hypothesis, as the dummy variables are specified in the regression function under the null hypothesis. The alternative hypothesis is a trend stationary process with a structural break. Nonetheless, the Perron (1989) unit-root test has less power than the standard Dickey-Fuller type test when there is no break (although it is correctly sized asymptotically and is consistent whether there is a break or not). Moreover, the exogenous determination of the break date invalidates the distribution theory underlying classical unit root testing (see Christiano (1992)).

Zivot and Andrews (1992), hence forth the $Z A$ test, addresses this latter limitation. They endogenously determine the break date where the evidence is least compelling for the unit root null hypothesis and a dummy variable is included under the alternative hypothesis accordingly. In particular, the location of the dummy variable is determined sequentially by identifying the location which maximizes the absolute value of the t-statistic on the $\gamma$ coefficient in equation (2).

Lee and Strazicich $(2001,2004)$, hence forth the $L S$ test, indicate that endogenous break tests, such as the Zivot and Andrews (1992) contribution, do not allow for a break under the null hypothesis of a unit root. This limitation may result in size distortions in the presence of a unit root with a break, against the alternative of stationarity with a break, and suggests that there maybe some loss of statistical power (Nunes et al. 1997 and Perron 2005). In particular, researchers may conclude that the time series is trend stationary when in fact the series is non-stationary with a break. As a result, the $L S$ test provides a unit root test that not only endogenously determines whether there is a structural break but also allows the presence of a structural break under the null hypothesis of a unit root thus avoiding these statistical power and size difficulties. The $L S$ Lagrange Multiplier unit root test is formulated on Equation (4), as outlined above. 
Finally, it has been noted that selecting the unit-root null hypothesis imposes an onerous obligation on the data to reject the null hypothesis should the data generating process be trend stationary. As a result Kwiatkowski et al. (1992), henceforth KPSS, provide a Lagrange Multiplier test where the null hypothesis of stationarity about a deterministic trend is assessed against the alternate of a difference stationary series instead of the conventional approach of a null hypothesis of a unit root.

\section{Data and Empirical Results}

\subsection{Data}

Our data includes daily closing prices on EU Allowance spot prices and futures contracts sourced on the Bluenext exchange and on the European Climate Exchange, respectively. The spot contracts span the phases I and II of the EU ETS, and extend from 24 June 2005 through to 28 July 2009. In total, there are ten futures contracts with maturity dates in December each year, 2005 through to 2014. The Bluenext exchange is the most liquid exchange for spot European Union Allowances and the European Climate Exchange is the most liquid exchange for carbon derivatives (see Alberola et al. (2008)). Further details regarding these price series are available in the appendix.

\subsection{Empirical Results}

In Table 1 the summary statistics are presented, including the number of observations recorded, the first through fourth unconditional statistical moments and hypotheses tests concerning the null hypotheses of normality (the Jarque Bera test) and homoskedasticity (a Lagrange Multiplier test for fourth order autoregressive heteroskedasticity or the ARCH test). The samples presented differ significantly in length, from 168 observations on the futures contracts which expire December 2005 to the 707 observations on the Bluenext spot contracts during the period 2005 through to 2007 . The measurements of mean and variance are comparable across the contracts except in the instances of the December 2006 and December 2007 futures contracts as well as the Bluenext spot contract (2005-2007). These latter contracts appear to have experienced significant declines in price as a result of the excessive allowances held in April 2006. ${ }^{3}$ All contracts exhibit statistically significant deviations from normality as well as heteroskedasticity.

3 As outlined in Bredin and Muckley (2009), in April 2006, coincident to the unofficial release of the 2005 emissions data by some of the EU member states the price of EUAs collapsed. EU ETS spot prices had reached a high of 30.50 euro prior to April 2006. Following the official release by the EU commission on the $15^{\text {th }}$ May 2006, showing a larger than expected surplus in the market, the spot price fell to 15.63 euro on the $17^{\text {th }}$ May 2006. Given that banking EUA's was prohibited between phases, the price eventually converged to close to zero at the end of Phase 1. 
The results of the various unit root tests performed are presented in Table 2. Each test is performed over the full sample of data that is recorded. The $A D F$ test assesses the null hypothesis of a unit root and no linear trend. It indicates that all series of log prices fail to reject the null hypothesis, while the null is convincingly rejected in the case of the returns series. The $P P$ test is specified such that the null hypothesis contains a unit root while the alternative hypothesis is trend stationary. This test clearly presents similar test results to the $A D F$ test results. The $E R S$ test which enjoys significantly superior statistical power than the $A D F$ specification concurs across the series examined. Concerning structural breaks, the $Z A$ test endogenously determines the location of a structural break in the alternative hypothesis and also provides supportive evidence for the presence of a random walk class of process in the EUA prices. The $L S$ test further extends the $Z A$ test by allowing a structural break under the null hypothesis. This test also provides concurrent evidence with respect to the presence of a stochastic trend in the various price series.

The aforementioned tests have specified the null hypothesis as containing a unit root, thus the onus was on the data to reject the null hypothesis should the series not contain a unit root. Indeed, the widespread failure of unit root tests to reject the null hypothesis of a unit root, in the context of time series of aggregate economic data, may arise as a result of these tests having low power against relevant alternatives. As a result, the KPSS methodology specifies a null hypothesis that is trend stationary and an alternative hypothesis that contains a unit root. With this complementary approach, the results across the price series indicate that the price process follows a random walk rather than a trend stationary class of process.

Taken together, the empirical results gathered provide a compelling case for the presence of a stochastic trend across the Bluenext spot price series and the range of European Climate Exchange futures contracts of differing maturities during the period April 2005 through to July 2009.

\section{Conclusion}

Notwithstanding the bulk of evidence that indicates that aggregate economic series tend to adhere to a unit root process, European Union Allowances are a class of commodity which is unique. Specifically, in respect to EUA prices, there is intervention on the supply side with a view to curtailing greenhouse gas emissions. As a result, it is of particular interest whether this commodity exhibits a stochastic trend or whether it follows an (upwardly inclined) trend stationary process, as would be anticipated as a mechanism to incentivate a decline in the emission of greenhouse gases.

The most important results featured in this article may be described as follows. We extend the sample of data studied in the received literature from April 2005 through to July 2009 and hence we capture observations on 14 contracts with respect to EUA prices, 
including both spot and derivative contracts. Across the battery of unit root tests adopted, a compelling case emerges that the examined series exhibit a stochastic trend. This finding of a stochastic trend (a unit root) in EUA prices has two main implications. Firstly, it would indicate that price behavior is not coherent with declared European Union policy with regard to transiting to a low carbon economy. Rather, it is indicative of skepticism on the part of the European Union, concerning the recommendation of Stern (2006), that the benefits of strong, early action on climate change considerably outweigh the costs. According to Stern (2006) this is an oversight, and if pursued on a global scale, it would imply a severe decline in global gross domestic product in the order of twenty percent, by the end of the $21^{\text {st }}$ century. Secondly, this finding supports the adoption of the variety of modeling techniques used in the extant literature (e.g. Alberola et al. (2008, 2009a, 2009b) and Daskalakis et al. (2009)), with a view to better understanding the behavior of EUA prices over time.

Nonetheless, clearly a number of difficulties remain. It may be of particular interest to remove the observations in April 2006 coinciding with the compliance break which instigated the collapse in the level of the EUA prices. Furthermore, there may be multiple structural breaks in the series that should also be controlled for. Finally, the suite of unit root tests adopted in this article do not control for heteroskedasticity (see Seo (1999)). We leave the development of our set of adopted methodologies, in the context of EUA prices, to further work.

\section{References}

Alberola, E., Chevallier, J., Cheze, B. (2008), "Price Drivers and Structural Breaks in European Carbon Prices 2005-2007”, Energy Policy, 36 (2), 787-797.

Alberola, E., Chevallier, J. and Cheze, B. (2009a), “European Carbon Price Fundamentals in 2005-2007: the Effects of Energy Markets, Temperatures and Sectorial Production", forthcoming in Journal of Policy Modelling.

Alberola, E., Chevallier, J., Cheze, B. (2009b), “The EU Emission Trading Scheme: Disentan-gling the Effects of Industrial Production and $\mathrm{CO}_{2}$ Emission on Carbon Prices", forthcoming in Economie Internationale.

Benz, E. and Trück, S. (2009), "Modelling the Price Dynamics of $\mathrm{CO}_{2}$ Emission Allowances", Energy Economics, 31, 2-15.

Bredin, D. and Muckley, C. (2009), "An Analys is of the EU Emission Trading Scheme", UCD School of Business Working Paper Series.

Christiano, L.J. (1992), "Searching for a Break in GNP”, Journal of Business and Economic Statistics, 10, 237-249. 
Daskalakis, G., Psychoyios, D., and Markellos, R.N. (2009), "Modelling $\mathrm{CO}_{2}$ emission Allowance prices and derivatives: Evidence from the European trading scheme", forthcoming, Journal of Banking and Finance.

Dickey, D.A and Fuller W.A. (1979) "Distributions of the Estimators for Autoregressive Time Series with a Unit Root”, Journal of American Statistical Association, 74 (366), 427-481.

Dickey, D.A and Fuller, W.A. (1981), "Likelihood Ratio Statistics for Autoregressive Time Series with a Unit Root”, Econometrica, 49 (4), 1057-1072.

Elliot, G., Rothenberg, T. and J.H. Stock (1996), "Efficient Tests for an Autoregressive Unit Root", Econometrica 64 (4), 813-836.

Kwiatkowski, D., Phillips, P.C.B., Schmidt, P. and Shin, Y. (1992), “Testing the null hypothesis of stationarity against the alternative of a unit root", Journal of Econometrics, 54, 159-178.

Lee, J. and Strazicich, M.C. (2001), "Break Point Estimation and Spurious Rejections with Endogenous Unit Root Tests", Oxford Bulletin of Economics and Statistics 63, 535-558.

Lee, J. and Strazicich, M.C. (2003), "Minimum LM Unit Root Test with Two Structural Breaks", Review of Economics and Statistics, 63, 1082-1089.

Lee, J., Strazicich, M.C. (2004), “Minimum LM Unit Root Test with One Structural Break", Appelation State University working paper series.

Nelson, C.R. and Plosser, C.I. (1982), "Trends and random walks In Macroeconomic Time Series", Journal of Monetary Economics, 10, 139-162.

Nunes, L., Newbold, P. and Kuan, C. (1997), "Testing for Unit Roots with Breaks: Evidence on the Great Crash and the Unit Root Hypothesis Reconsidered", Oxford Bulletin of Economics and Statistics, 59, 435-448.

Paolella, M.S. and Taschini, L. (2008), “An Econometric Analysis of Emission Trading Allowances", Journal of Banking and Finance, 32, 2022-2032.

Perron, P. (1989), "The great crash, the oil price shock, and the unit root hypothesis", Econometrica 57, 1361-1401.

Perron, P. (2005), "Dealing with Structural Breaks", Mimeo in the Vol. 1, Handbook of Econometrics: Econometric Theory.

Phillips, P. and Perron, P. (1988), “Testing for a Unit Root in Time Series Regression”, Biometrica, 75, 335-346.

Seo, B. (1999), "Distribution theory for unit root tests with conditional heteroskedasticity", Journal of Econometrics 91, 113-144.

Stern, N. (2006), "Short Executive Summary", Stern Review Report on the Economics of Climate Change, pre-publication edition, HM Treasury, $<$ http://www.hmtreasury.gov.uk/d/CLOSEDSHORTexecutivesummary.pdf $>$, 28.08.2009. 
Zivot, E. and Andrews, K. (1992), "Further Evidence on the Great Crash, the Oil Price Shock and the Unit Root Hypothesis", Journal of Business, Economics and Statistics 10 (10), 251-270.

\section{Appendix}

\begin{tabular}{ll}
\hline \hline Series & Description \\
\hline Spot & The Bluenext exchange is the most liquid spot exchange for European Union \\
Allowances (EUAs). One EU Allowance is an entitlement to emit one tonne of \\
carbon dioxide. We examine BNS EUA 05-07 and BNS EUA 08-12 contracts which \\
correspond to Bluenext spot prices for EUAs during Phase I (2005-07) and Phase II \\
(2008-12) of the EUA market. EUAs are issued by member states according to their \\
National Allocation Plans. Minimum price tick size is .01 euro per tonne and \\
minimum volume tick is 1000 tonnes. \\
Data corresponding to EUA BNS $(05-07)$ extend from $24^{\text {th }}$ June 2005 to $25^{\text {th }}$ April \\
2008 and data corresponding to EUA BNS $(08-12)$ extend from $26^{\text {th }}$ February 2008 to \\
28 July 2009. \\
The European Climate Exchange is the most liquid exchange for the trading of \\
European Union Allowances (EUAs) futures contracts. Contracts expiring and settled \\
mid-December are considered over the range of maturities 2005 through to 2014. \\
Trade occurs on the ICE (Inter Continental Exchange) futures electronic platform or \\
through a confirmed independent software vendor. Minimum tick size is .01 euro per \\
tonne and a unit of trading corresponds to 1 lot of 1000 tonnes of $C O 2$ EU allowances. \\
Data corresponding to contracts expiring mid-December 2005 through to mid- \\
December 2008 extends from $22^{\text {nd }}$ April 2005 to $19^{\text {th }}$ December $2005,30^{\text {th }}$ May 2006, \\
1 $7^{\text {th }}$ December 2007 and $15^{\text {th }}$ December 2008 , respectively. The latest observation of \\
contracts expiring mid-December 2009 to 2012 is 24 July 2009. Observations on \\
these latter contracts were first recorded $22^{\text {nd }}$ April 2005 . Data corresponding to \\
contracts expiring mid-December 2013 and 2014 extends from $8^{\text {th }}$ April 2008 through \\
to $24^{\text {th }}$ July 2009 .
\end{tabular}


Table: 1

\section{Summary Statistics}

Full Sample

\begin{tabular}{lrrrcrrr}
\hline \hline Series & Obs & Mean & Variance & Skewness & Exc. Kurtosis & Jarque Bera & Arch \\
\hline BNS0507 & 707 & -1.09 & 92.11 & $-0.67^{*}$ & $15.99^{*}$ & $7591.44^{*}$ & $108.73^{*}$ \\
BNS0812 & 360 & -0.12 & 8.65 & -0.12 & $1.20^{*}$ & $22.43^{*}$ & $353.26^{*}$ \\
Dec05sett & 168 & 0.13 & 8.01 & $-1.81^{*}$ & $9.49^{*}$ & $722.78^{*}$ & $30.07^{*}$ \\
Dec06sett & 280 & 0.02 & 28.29 & $0.74^{*}$ & $33.88^{*}$ & $13421.03^{*}$ & $46.50^{*}$ \\
Dec07sett & 680 & -1.09 & 115.33 & $-3.18^{*}$ & $73.27^{*}$ & $153232.44^{*}$ & $217.40^{*}$ \\
Dec08sett & 705 & 0.03 & 9.05 & $-1.45^{*}$ & $16.14^{*}$ & $7898.99^{*}$ & $22.51^{*}$ \\
Dec09sett & 707 & 0.03 & 8.81 & $-1.36^{*}$ & $16.02^{*}$ & $7779.88^{*}$ & $23.89^{*}$ \\
Dec10sett & 705 & 0.04 & 8.60 & $-1.34^{*}$ & $15.59^{*}$ & $7353.8^{*}$ & $25.88^{*}$ \\
Dec11sett & 705 & 0.04 & 8.51 & $-1.31^{*}$ & $14.70^{*}$ & $6550.15^{*}$ & $28.99^{*}$ \\
Dec12sett & 705 & 0.05 & 8.73 & $-1.30^{*}$ & $13.60^{*}$ & $5634.19^{*}$ & $30.70^{*}$ \\
Dec13sett & 331 & -0.14 & 6.79 & 0.08 & $1.38^{*}$ & $26.43^{*}$ & $39.77^{*}$ \\
Dec14sett & 331 & -0.13 & 6.06 & 0.04 & $1.28^{*}$ & $22.65^{*}$ & $36.80^{*}$ \\
\hline \hline
\end{tabular}

Notes. The Panel contains summary statistics regarding the first, second, third and fourth moments of the EU Allowance continuously compounded return distributions. It also contains hypotheses tests concerning the null of normality (the Jarque Bera test) and the null of homoscedasticity (the $A R C H$ test). The full sample period assessed is from the 24th April 2005 to the 28th July 2009. Each individual contract is specific to a time window as outlined in the description of data appendices. A * indicates statistical significance at the $5 \%$ level. 
Is There A Stochastic Trend in European

Union Emission Trading Scheme Prices?

Flgure 1: BlueNext Exchange EUA spot prices

Buenext Spot 05-07

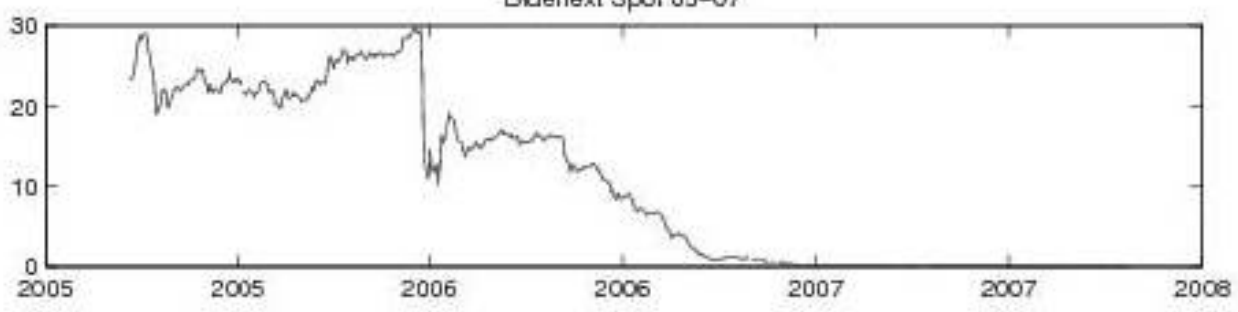

Buenext Spot 08-12

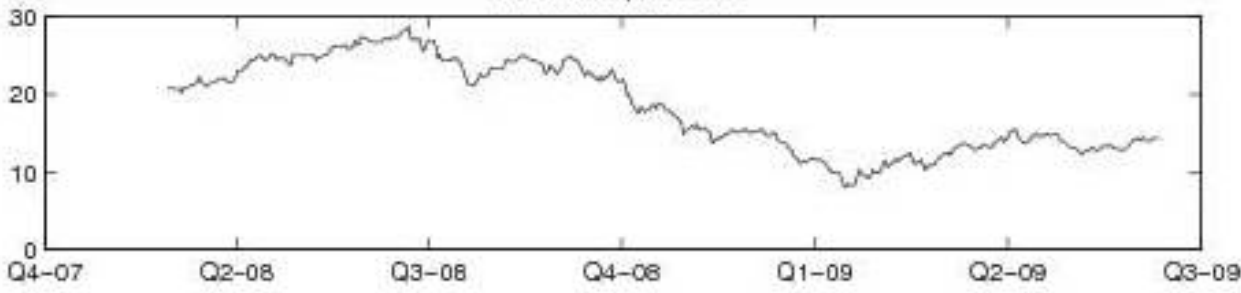

Figure 2: European Climate Exchange EUA Futures
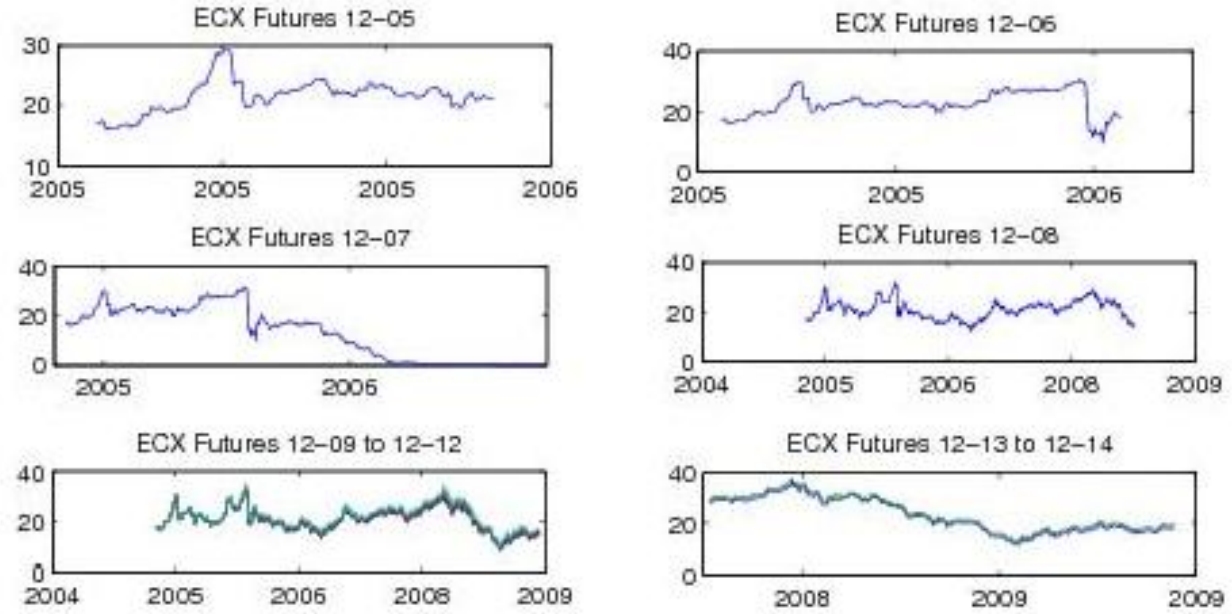
Table: 2

\section{Unit Root Tests}

\begin{tabular}{lrrr}
\hline \hline Series & \multicolumn{1}{c}{ ADF } & \multicolumn{1}{c}{ PP } & \multicolumn{1}{c}{ ERS } \\
\hline BNS0507 & $4.35\left[264.89^{*}\right]$ & $-1.93\left[-31.01^{*}\right]$ & $-0.75\left[-30.63^{*}\right]$ \\
BNS0812 & $1.59\left[111.32^{*}\right]$ & $-1.74\left[-16.46^{*}\right]$ & $-1.19\left[-16.41^{*}\right]$ \\
Dec05sett & $2.64\left[46.18^{*}\right]$ & $-2.09\left[-9.65^{*}\right]$ & $-1.25\left[-8.60^{*}\right]$ \\
Dec06sett & $2.97\left[115.76^{*}\right]$ & $-2.55\left[-15.35^{*}\right]$ & $-1.83\left[-14.42^{*}\right]$ \\
Dec07sett & $6.23\left[220.35^{*}\right]$ & $-0.63\left[-27.59^{*}\right]$ & $-0.01\left[-14.12^{*}\right]$ \\
Dec08sett & $3.74\left[365.08^{*}\right]$ & $-2.64\left[-27.13^{*}\right]$ & $-1.94\left[-21.43^{*}\right]$ \\
Dec09sett & $3.09\left[395.24^{*}\right]$ & $-2.35\left[-28.19^{*}\right]$ & $-1.59[-22.64 *]$ \\
Dec10sett & $3.09\left[403.00^{*}\right]$ & $-2.36\left[-28.48^{*}\right]$ & $-1.59\left[-22.77^{*}\right]$ \\
Dec11sett & $3.12\left[405.93^{*}\right]$ & $-2.37\left[-28.58^{*}\right]$ & $-1.58\left[-22.81^{*}\right]$ \\
Dec12sett & $3.15\left[421.19^{*}\right]$ & $-2.40\left[-29.11^{*}\right]$ & $-1.61\left[-23.25^{*}\right]$ \\
Dec13sett & $1.02\left[97.74^{*}\right]$ & $-1.46\left[-15.17^{*}\right]$ & $-1.17\left[-15.23^{*}\right]$ \\
Dec14sett & $0.80\left[97.84^{*}\right]$ & $-1.43\left[-15.07^{*}\right]$ & $-1.15[-15.14 *]$ \\
\hline & & & \\
Series & $\mathbf{Z A}$ & $\mathbf{L S}$ & KPSS \\
BNS0507 & $3.86\left[23.39^{*}\right]$ & $2.77\left[12.09^{*}\right]$ & $2.91 *[0.09]$ \\
BNS0812 & $3.44\left[16.34^{*}\right]$ & $2.43\left[8.13^{*}\right]$ & $0.75^{*}[0.17]$ \\
Dec05sett & $5.77\left[10.35^{*}\right]$ & $4.13\left[6.39^{*}\right]$ & $0.46 *[0.04]$ \\
Dec06sett & $3.23\left[15.34^{*}\right]$ & $4.29\left[6.14^{*}\right]$ & $0.63^{*}[0.10]$ \\
Dec07sett & $3.42\left[21.28^{*}\right]$ & $3.53\left[8.26^{*}\right]$ & $3.23 *[0.04]$ \\
Dec08sett & $3.80\left[27.22^{*}\right]$ & $3.75\left[13.05^{*}\right]$ & $1.41^{*}[0.06]$ \\
Dec09sett & $3.72\left[28.25^{*}\right]$ & $3.66\left[13.59^{*}\right]$ & $1.27 *[0.05]$ \\
Dec10sett & $3.72\left[28.53^{*}\right]$ & $3.72\left[13.48^{*}\right]$ & $1.25^{*}[0.05]$ \\
Dec11sett & $3.74\left[28.64^{*}\right]$ & $3.74\left[13.46^{*}\right]$ & $1.23 *[0.05]$ \\
Dec12sett & $3.73\left[29.17^{*}\right]$ & $3.73\left[13.52^{*}\right]$ & $1.20^{*}[0.04]$ \\
Dec13sett & $3.74\left[15.25^{*}\right]$ & $2.3\left[8.40^{*}\right]$ & $0.75^{*}[0.16]$ \\
Dec14sett & $3.77\left[15.27^{*}\right]$ & $2.27\left[8.51^{*}\right]$ & $0.77^{*}[0.17]$ \\
\hline \hline & & & \\
\hline
\end{tabular}

Notes. The Panels contain unit root hypotheses tests on the logarithmic EU Allowance prices and the corresponding continuously compounded return distributions. The full sample period assessed is from the $24^{\text {th }}$ April 2005 to the $28^{\text {th }}$ July 2009. Each individual contract is specific to a time window as outlined in the description of data appendices. The hypotheses tests performed are the augmented Dickey-Fuller test $(A D F, 1979$, 1981), the Phillips-Perron test (PP, 1988), the Zivot and Andrews test $(Z A, 1992)$, the Elliot, Rothenberg and Stock test (ERS, 1996), the Kwiatkowski, Phillips, Schmidt and Shintest (KPSS, 1992), the Lee and Strazicich test $(L S, 2004)$. The test statistics for each of the series in logarithmic differences are reported in square brackets, while the test statistics with respect to levels are adjacent. A * indicates statistical significance at the $5 \%$ level. 